\title{
Glycogen Levels and Energy Status of the Liver of Fasting Rats with Diabetes Types 1 and 2
}

\author{
Denise Silva de Oliveira, Ciomar Aparecida Bersani Amado, Mirian Carvalho Martini, \\ Fumie Suzuki-Kemmelmeier and Adelar Bracht* \\ Laboratório de Metabolismo Hepático; Universidade Estadual de Maringá; adebracht@uol.com.br; \\ 87020-900; Maringá - PR - Brasil
}

\begin{abstract}
Glycogen levels and the energy status of livers from fasting rats with diabetes types 1 and 2 were measured. After a $24 \mathrm{~h}$ fast, the hepatic glycogen levels of rats with diabetes 1 and diabetes 2 were, 18.7 and 2.6 times higher, respectively, than those of livers from the normal rats. In diabetes1 rats, the glycogen levels decreased when the fasting period was extended to 48 and $72 \mathrm{~h}$. The opposite occurred with the control and diabetes 2 rats. Consistently, glucose release by the perfused livers from diabetes1 rats was considerably higher during at least 60 minutes after initiating perfusion. The hepatic ATP content of diabetes 1 rats was similar to that of the control rats; in diabetes 2 rats, the hepatic ATP content was increased. It could be concluded that regulation of glycogen deposition and degradation in rats with diabetes 1 differed markedly from that of rats with diabetes 2 which, in turn, behaved similarly to normal healthy rats.
\end{abstract}

Key words: Diabetes type 1, diabetes type 2, rats, hepatic glycogen, hepatic energy status

\section{INTRODUCTION}

In spite of decades of experimental efforts, there are many aspects of the hepatic metabolism of diabetic animals that have not yet be satisfactorily clarified. Contradictory observations are frequently found in the specialized literature. For example, earlier experiments with isolated hepatocytes of alloxan diabetic rats (diabetes type 1) have led to the conclusion that hepatic gluconeogenesis from alanine, pyruvate and fructose is considerably increased in this preparation (Wagle et al., 1975). Experiments with the isolated perfused rat liver, however, concluded that gluconeogenesis from lactate, glycerol and sorbitol is not affected by alloxan and streptozotocin induced diabetes, whereas gluconeogenesis from alanine is absent in these animals (Ferraz et al., 1997). Kleckner et al. (1987), on the other hand, have found diminished rates of gluconeogenesis from lactate in perfused livers from alloxan diabetic rats (diabetes type 1). A common characteristic of all these experiments is that livers from rats with diabetes type 1 present high rates of basal glucose release, i.e., before the introduction of the gluconeogenic substrates. This could be due to glycogenolysis or gluconeogenesis from endogenous substrates. Actually, it has been reported that the glycogen levels of rats with diabetes 1 after a $24 \mathrm{~h}$ fast are much higher than those in normal healthy rats (Gannon and Nuttall, 1997), so that the elevated basal rates of glucose release observed by several authors could be the result of glycogenolysis.

\footnotetext{
${ }^{*}$ Author for correspondence
} 
The present work attempted to investigate how the hepatic glycogen levels of diabetic rats behave during various fasting periods. It is known that in healthy rats, the hepatic glycogen levels tend to increase again after a $48 \mathrm{~h}$ fast (Sasse, 1975; BoisJoyeux et al., 1987), a phenomenon which reflects most probably increased gluconeogenesis from endogenous substrates such as glutamine (Mouterde et al., 1992). In this respect, the behavior of diabetic rats is not known and an investigation of this question could be important for two main reasons. Firstly, it would reveal hitherto unknown aspects of the metabolic behavior of diabetic animals, especially if the study is extended to rats with diabetes type 2 in addition to rats with diabetes type 1 . Second, it should also produce basic information which can be used for planning future experiments in which gluconeogenesis from several substrates in fasting diabetic rats will be investigated. For this reason, in the present work, the hepatic glycogen levels of normal rats and rats with diabetes types 1 and 2 were followed over a period of $72 \mathrm{~h}$ after food deprivation. In addition, other parameters were measured such as liver weight and the hepatic energy status.

\section{MATERIAL AND METHODS}

\section{Materials}

All the enzymes and coenzymes used in the enzymatic assays were purchased from Sigma Chemical Co. (St Louis, USA). All the standard chemicals were from the best available grade (98$99.8 \%$ purity).

\section{Animals and diabetes induction}

Male Wistar rats weighing 220-250 g fed with a standard laboratory diet $\left(\mathrm{Nuvilab}^{\circledR}\right)$ were used in all perfusion experiments. Diabetes type 1 (diabetes1) was induced by injecting adult rats with streptozotocin (Gannon and Nuttall, 1997). Streptozotocin was dissolved in citrate buffer (10 $\mathrm{mM} ; \mathrm{pH} 4.5$ ) and a single dose of $50 \mathrm{mg} / \mathrm{kg}$ was injected intraperitoneally. After 12 days, blood glucose of fed rats was measured and animals presenting glycemic levels equal or above $16 \mathrm{mM}$ in the fed state were selected for the experiments. Control rats were injected intraperitoneally with citrate buffer (10 mM, pH 4.5).

Diabetes mellitus type 2 (diabetes2) was induced as described by Portha et al. (1974). Male newborn (2 days old) Wistar rats were injected intraperitoneally with streptozotocin $(150 \mathrm{mg} / \mathrm{kg})$ dissolved in citrate buffer (10 mM; pH 4.5). Seven weeks later, diabetes was confirmed by urine glucose levels, $24 \mathrm{~h}$ urinary volume and water intake. The protocol for these experiments was approved by the Ethics Committee for Animal Experimentation of the University of Maringá.

\section{Liver perfusion}

Hemoglobin-free, non-recir-culating perfusion was done according to the technique described elsewhere (Scholz and Bücher, 1965; KelmerBracht et al., 2002). For the surgical procedure, the rats were anesthetized by intraperitoneal injection of sodium thiopental $(50 \mathrm{mg} / \mathrm{kg})$. After cannulation of the portal and cava veins the liver was positioned in a plexiglass chamber. The flow was maintained constant by a peristaltic pump (Minipuls 3, Gilson, France) and was adjusted between 30 and $35 \mathrm{ml} \mathrm{min}{ }^{-1}$, depending on the liver weight. The perfusion fluid was Krebs/Henseleit-bicarbonate buffer ( $\mathrm{pH}$ 7.4), saturated with a mixture of oxygen and carbon dioxide (95:5) by means of a membrane oxygenator with simultaneous temperature adjustment at $36^{\circ} \mathrm{C}$. The composition of the Krebs/ Henseleit-bicarbonate buffer is the following: 115 $\mathrm{mM} \mathrm{NaCl}, 25 \mathrm{mM} \mathrm{NaHCO} 3,5.8 \mathrm{mM} \mathrm{KCl}, 1.2$ $\mathrm{mM} \mathrm{Na} \mathrm{SO}_{4}, 1.18 \mathrm{mM} \mathrm{MgCl} 2,1.2 \mathrm{mM} \mathrm{NaH}_{2} \mathrm{PO}_{4}$ and $2.5 \mathrm{mM} \mathrm{CaCl} 2$. Glucose in the outflowing perfusate was measured enzymatically (Bergmeyer and Bernt, 1974).

\section{Assays}

Glycogen was determined in freshly isolated livers from anesthetized rats (sodium thiopental, 50 $\mathrm{mg} / \mathrm{kg}$ ). Portions of approximately $2 \mathrm{~g}$ were freeze-clamped with liquid nitrogen. This sample was homogenized and extracted with $8 \mathrm{ml}$ of $6 \%$ $\mathrm{HClO}_{4}$. The supernatant was neutralized with $5 \mathrm{~N}$ $\mathrm{K}_{2} \mathrm{CO}_{3}$ and used for the enzymatic glycogen assay (Kepler and Decker, 1974).

For the measurement of the cellular adenine nucleotide contents, livers were freeze-clamped in liquid nitrogen, homogenized and extracted with perchloric acid. The neutralized extracts were used for the enzymatic assay of ATP (Lamprecht and Trautschold, 1974), ADP and AMP (Jaworek et al., 1974).

Plasma concentrations of glucose, urea and ammonia were assayed by collecting blood from 
the vena cava. Blood was collected by means of a syringe containing heparin after a surgical incision into the abdominal cavity of anaesthetized rats (sodium thiopental, $50 \mathrm{mg} / \mathrm{kg}$ ). After sedimenting the blood cells in a refrigerated centrifuge (10 minutes, $7000 \mathrm{rpm})$, plasma was used for the enzymatic assays of urea (Gutmann and Bergmeyer, 1974), ammonia (Kearney and Kun, 1974) and glucose (Bergmeyer and Bernt, 1974).

\section{Treatment of data}

Statistical analysis of the data was done by means of the Statistica ${ }^{\mathrm{TM}}$ program (Statsoft ${ }^{\circledR}, 1998$ ). Mono- or two-way variance analysis was applied according to context with post-hoc testing; $\mathrm{p}<$ 0.05 was adopted as a criterion of significance.

\section{RESULTS AND DISCUSSION}

Table 1 shows some characteristics of the plasma of the rats with diabetes types 1 and 2 in the fasted state. After a fasting period of $24 \mathrm{~h}$ the plasma glucose concentrations of both rats with diabetes 1 and 2 were $57.3 \%$ and $23.1 \%$, respectively, above the normal values. These values were smaller than those ones normally found in fed diabetic rats (Portha et al., 1974; Gannon and Nuttall, 1997). The ammonia and urea concentrations of the rats with diabetes2 were normal, but rats with diabetes 1 presented considerably higher urea $(+401.5 \%)$ and ammonia (+90.9\%) concentrations. These higher blood urea and ammonia concentrations in rats with diabetes 1 are probably reflecting the higher rates of amino acid degradation (Squires et al., 1997), which also increase the urinary urea excretion (Kim et al., 2005). However, the increased urea excretion was combined with a much higher urinary volume and lower urinary urea concentrations (Kim et al., 2005). The high blood urea concentrations are, thus, the consequence of both higher amino acid catabolism and impaired renal function. Investigations about the urea cycle in the liver of diabetes 1 rats would be highly desirable because this tissue is the main source of urea. It is interesting to note that rats with diabetes 2 did not present such visible alterations in nitrogen catabolism.

Fig. 1 illustrates the changes in the hepatic glycogen contents and the relative liver weights as a function of the fasting time. Rats with diabetes 1 presented higher liver weights per body weight (g liver per 100 gram body weight) after a $24 \mathrm{~h}$ fast. The difference vanished, however, when the fasting period was increased. For rats with diabetes2, the relative liver weight was similar to that of the control rats, irrespective of the fasting period. The higher liver weights of diabetes 1 rats after a $24 \mathrm{~h}$ fast could be caused, partly at least, by their high glycogen contents because of the pronounced hygroscopic properties of this polysaccharide. As shown in Fig. 1, rats with type 1 diabetes contained high levels of hepatic glycogen after a $24 \mathrm{~h}$ fast, with a diabetes $1 /$ control ratio equal to 18.7 . It should be noted that the relatively high levels of hepatic glycogen in $24 \mathrm{~h}$ fasted diabetes 1 rats, $55.8 \mu \mathrm{mol} \mathrm{g}^{-1}$, were actually much lower than the maximal levels normally attained by the normal fed rats which may reach values as high as $330 \mu \mathrm{mol} \mathrm{g}{ }^{-1}$ (Bazotte et al., 1990). Rats with diabetes type 2 also presented higher hepatic glycogen levels, namely $8.2 \mu \mathrm{mol}$ $\mathrm{g}^{-1}$, but the diabetes $2 /$ control ratio was only 2.76 . Prolongation of the fasting period produced decreases in the glycogen levels of rats with diabetes 1 and increases in the glycogen levels of rats with diabetes 2 as well as in control rats. At 72 $\mathrm{h}$, all the groups presented similar hepatic glycogen concentrations. These observations mean that no net glycogenesis took place in diabetes 1 rats during the period between 24 and $72 \mathrm{~h}$ fast. Net glycogen synthesis, however, must have occurred in the control and diabetes 2 rats during the same period. In the absence of exogenous sources, this net glycogen accumulation must have occurred at the expense of gluconeogenesis, which in turn, depended exclusively on endogenous sources.

Since diabetes 1 rats presented relatively high glycogen levels, glucose release by the perfused livers of such animals should be relatively pronounced if no exogenous gluconeogenic substrates were added to the perfusion fluid. This hypothesis was tested by perfusing the livers from both control and diabetes1 animals with substratefree perfusion fluid. Sampling of the outflowing perfusate for glucose assay was initiated immediately after connecting the liver to the perfusion apparatus. 


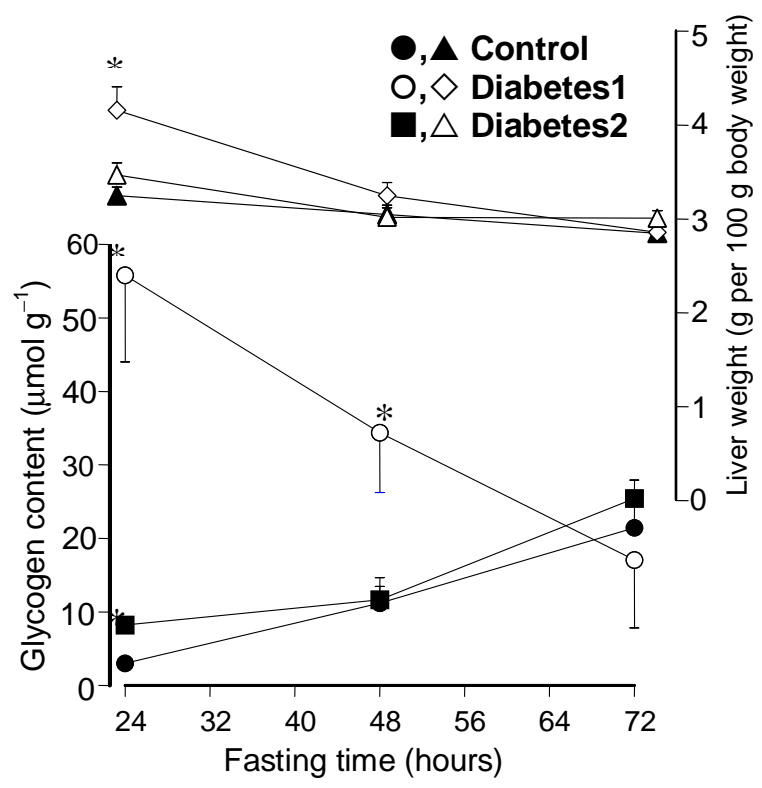

Figure 1 - Evolution of liver weight and glycogen content as a function of the fasting time in control rats and rats with diabetes 1 and 2. Statistically significant differences between diabetes 1 and control or diabetes 2 and control are indicated by asterisks $(\mathrm{p}<0.05)$. Bars represent mean standard errors of a minimum of 3 and a maximum of 17 determinations

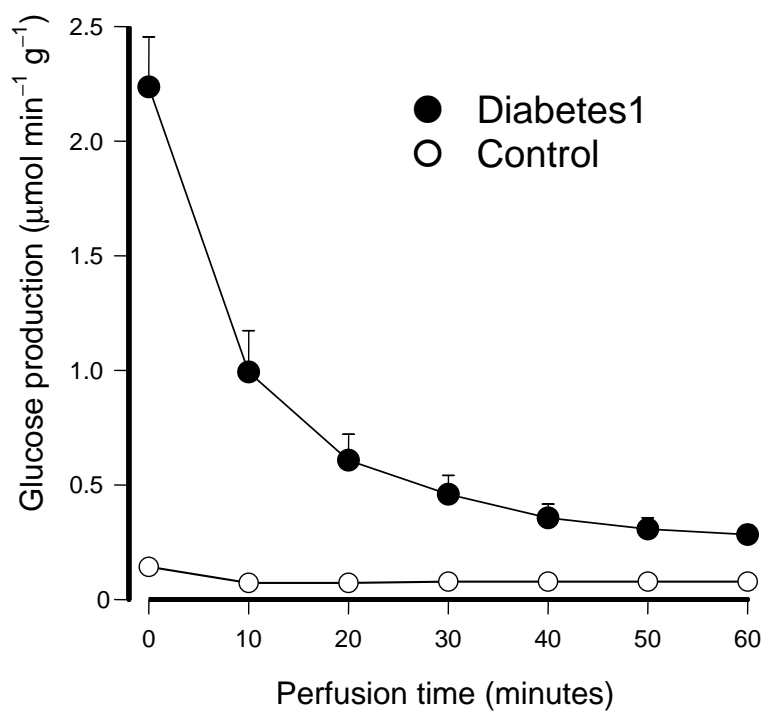

Figure 2 - Rates of glucose production by rat livers as a function of time after connecting the liver to the perfusion apparatus. Livers were perfused with Krebs/Henseleit-bicarbonate buffer ( $\mathrm{pH}$ 7.4). Sampling of the outflowing perfusate was initiated immediately after connecting the liver to the perfusion apparatus. Glucose in the outflowing perfusate was measured enzymatically. Data are means \pm SEM of 6 (control) and 12 (diabetes1) liver perfusion experi-ments 
Table 1 - Plasma concentrations of glucose, ammonia and urea in 24-h fasted control and diabetic rats. Blood was collected and analyzed enzymatically. Data are means \pm SEM. Asterisks are used to indicate values differing statistically from the corresponding controls according to the Student-Newman-Keuls test applied after variance analysis $(p<0.05)$.

\begin{tabular}{lccc}
\hline Compound & Control & Diabetes1 & Diabetes2 \\
\hline & $\mathbf{m M}$ & & \\
\cline { 2 - 4 } Glucose & $4.80 \pm 0.14(\mathrm{n}=5)$ & $7.55 \pm 0.47 *(\mathrm{n}=18)$ & $5.91 \pm 0.25^{*}(\mathrm{n}=9)$ \\
Ammonia & $0.11 \pm 0.01(\mathrm{n}=8)$ & $0.21 \pm 0.03 *(\mathrm{n}=11)$ & $0.14 \pm 0.01(\mathrm{n}=7)$ \\
Urea & $4.83 \pm 0.26(\mathrm{n}=8)$ & $24.22 \pm 1.68 *(\mathrm{n}=11)$ & $4.74 \pm 0.42(\mathrm{n}=7)$ \\
\hline
\end{tabular}

Table 2 - Hepatic contents of adenine nucleotides in 24-h fasted control and diabetic rats. The liver freeze-clamped in liquid nitrogen, extracted with cold perchloric acid and the adenine nucleotides were determined enzymatically. Data are means \pm SEM. Asterisks are used to indicate values of the diabetes 1 or diabetes 2 conditions differing statistically from the corresponding controls according to the Student-Newman-Keuls test applied after variance analysis $(p<0.05)$.

\begin{tabular}{lcccc}
\hline Animal condition & ATP & ADP & AMP & Total nucleotides \\
\hline & \multicolumn{1}{c}{$\boldsymbol{\mu m o l}$ (gram liver wet weight) } & & \\
\cline { 2 - 5 } Control $(\mathrm{n}=13)$ & $1.42 \pm 0.17$ & $1.16 \pm 0.05$ & $0.35 \pm 0.05$ & $2.93 \pm 0.11$ \\
Diabetes1 $(\mathrm{n}=4)$ & $1.29 \pm 0.12$ & $0.90 \pm 0.03^{*}$ & $0.32 \pm 0.07$ & $2.51 \pm 0.10^{*}$ \\
Diabetes2 $(\mathrm{n}=9)$ & $2.16 \pm 0.08^{*}$ & $1.11 \pm 0.02$ & $0.25 \pm 0.02$ & $3.52 \pm 0.08^{*}$ \\
\hline
\end{tabular}

The results are shown in Fig. 2. Glucose release from the control livers was small and almost constant over the 60 minutes perfusion time. Livers from diabetes1 animals, however, showed initially very high rates of glucose release, with a diabetes $1 /$ control ratio equal to 15.6 at time zero. These high rates diminished progressively during the subsequent time and the diabetes $1 /$ control ratio was reduced to 3.59 at 60 minutes perfusion time. This decrease represents most probably the progressive diminution of the glycogen stores in consequence of glycogenolysis.

Table 2 shows the tissue contents in adenine nucleotides of livers from control, diabetes 1 and diabetes 2 animals after a fasting period of $24 \mathrm{~h}$. Diabetes1 rats presented a small tendency toward smaller ATP levels, but only the ADP levels were statistically smaller than those found in control livers. As a consequence, however, the sum of total nucleotides (ATP+ADP+AMP) was also somewhat smaller in diabetes 1 rats. Diabetes 2 rats, on the other hand, presented significantly higher ATP levels with no significant changes in the AMP and ADP levels. In consequence, these rats also presented a higher content in total adenine nucleotides. These results did not reveal any significant ATP depletion in diabetic rats after a
$24 \mathrm{~h}$ fast. The reasons for the higher ATP levels in the livers from diabetes 2 rats cannot be inferred from the present data, but the phenomenon is clearly worth of more specific investigations.

It is quite apparent that investigations concerning gluconeogenesis in livers from diabetes 1 rats must take into account the relatively high glycogen levels which are unavoidably associated to glycogenolysis in the perfused liver, with high and declining rates of glucose release. For distinguishing gluconeogenesis from glycogenolysis under these conditions, it will be indispensable to use radioactive precursors, which allow to measure newly formed glucose in a specific manner. Alternatively, gluconeogenesis can also be evaluated if the glycogen levels are simultaneously measured so that the appropriate corrections can be done. Simple subtraction of the very high basal rates after infusion of a gluconeogenic substrate (Ferraz et al., 1997; Akimoto et al., 2000) is a highly risky procedure which is likely to lead to erroneous evaluations of the true gluconeogenic activities.

The relatively high hepatic glycogen levels of 24 h-fasted rats with diabetes type 1 are probably the consequence of the high glycogen synthase to glycogen phosphorylase activity ratio, as reported 
by several workers (Akatsuka et al., 1983; Rao et al., 1995; Gannon and Nuttall, 1997). No such data are available about rats with diabetes type 2 . However, taking into account that these rats present considerably lower glycogen levels when compared to rats with diabetes type 1 , it is conceivable that they also present lower glycogen synthase/glycogen phosphorylase levels. On the other hand, the progressive decrease of the hepatic glycogen levels in diabetes 1 rats when the fasting period was prolonged to $72 \mathrm{~h}$ could be reflecting also a progressive decrease in the glycogen synthase/ glycogen phosphorylase ratio, the opposite being more likely in healthy (control) and diabetes 2 rats. The phenomenon of increased glycogen accumulation after a prolonged fasting period, common to healthy and diabetes 2 rats, but contrasting with diabetes1 rats, is poorly understood. However, since glycogen synthesis under starvation depends essentially on the amino acid availability resulting from protein degradation, one can expect that amino acids are playing a regulatory role. Such a role has been attributed to glutamine based on specific experiments with hepatocytes isolated from rats after different fasting periods (Mouterde et al., 1992). In hepatocytes isolated from $72 \mathrm{~h}$ fasted rats, glutamine is more effective in stimulating glycogen synthase than after a $24 \mathrm{~h}$ fast. At the same time, the capacity of glutamine in stimulating glycogen phosphorylase, clearly present after a $24 \mathrm{~h}$ fast, is practically absent after a $72 \mathrm{~h}$ fasting period.

In conclusion, regulation of glycogen deposition and degradation during the prolonged fasting periods in rats with diabetes 1 differs markedly from that of rats with diabetes 2 which, in turn, behave similarly to normal healthy rats. There is little information available about the mechanisms underlying these differences, but data available about the influence of glutamine on glycogen synthase activation during prolonged starvation (Mouterde et al., 1992) suggest a crucial role for the amino acids resulting from proteolysis.

\section{RESUMO}

Teores de glicogênio e os estados energéticos de fígados de ratos com diabete dos tipos 1 e 2 foram medidos. Após um jejum de 24 horas os teores de glicogênio de ratos com diabete 1 e diabete 2 foram, respectivamente 18,7 e 2,6 vezes superiores àqueles de fígados de animais controle. Em ratos com diabete1 o conteúdo de glicogênio diminuiu quando o período de jejum foi prolongado para 48 e 72 horas. $\mathrm{O}$ oposto ocorreu em ratos controle e ratos com diabete2. Consistentemente, a liberação de glicose por fígados em perfusão isolada obtidos de ratos com diabete1 foi consideravelmente maior durante ao menos 60 minutos após o início da perfusão. O conteúdo hepático de ATP de ratos com diabete 1 foi similar àquele de ratos controle; em ratos com diabete2 o conteúdo hepático de ATP foi maior. Pode-se concluir que a regulação da deposição e degradação do glicogênio em ratos com diabete1 difere marcadamente daquela de ratos com diabete2, os quais, por seu turno, comportam-se similarmente a ratos normais $\mathrm{e}$ saudáveis.

\section{REFERENCES}

Akatsuka, A., Singh, T. J., Huang, K. P. (1983), Comparison of the liver glycogen synthase from normal and streptozotocin-induced diabetic rats. Arch. Biochem. Biophys. 220, 426-434.

Akimoto, L.S., Pedrinho, S.R., Lopes, G. and Bazotte, R.B. (2000), Rates of gluconeogenesis in perfused liver of alloxan-diabetic fed rats. Res. Comm. Mol. Pathol. Pharmacol., 107, 65-77.

Bazotte, R.B., Constantin, J., Hell, N.S. and Bracht, A. (1990), Hepatic metabolism of meal-fed rats: Studies in vivo and in the isolated perfused rat liver. Physiol. Behav., 48, 247-253.

Bergmeyer, H.U. and Bernt, E. (1974), Determination of glucose with glucose oxidase and peroxidase. InMethods of Enzymatic Analysis, ed. H.U. Bergmeyer, Verlag Chemie-Academic Press, WeinheimLondon, pp. 1205-1215.

Bois-Joyeux, B., Chanez, M., Peret, J. (1987), Changes in rat hepatic fructose 2,6bisphosphate and 6phosphofructo-2-kinase/fructose 2,6-bisphos-phatase activity during three days of consumption of a high protein diet or starvation. Diabete Metab., 13, 543548.

Ferraz, M., Brunaldi, K., Oliveira, C.E. and Bazotte, R.B. (1997), Hepatic glucose production from Lalanine is absent in perfused liver of diabetic rats. Res. Comm. Mol. Pathol. Pharmacol., 95, 147-155.

Gannon, M.C. and Nuttall, F.Q. (1997), Effect of feeding, fasting, and diabetes on liver glycogen synthase activity, protein, and mRNA in rats. Diabetologia, 40, 758-763. 
Gutmann, J. and Bergmeyer, H.U. (1974), Determination of urea with glutamate dehydrogenase as indicator enzyme. In-Methods of Enzymatic Analysis, ed. H.U. Bergmeyer,.Verlag Chemie-Academic Press, Weinheim-London, pp. 1794-1798.

Jaworek, D., Gruber, W. and Bergmeyer, H.U. (1974), Adenosine 5'-diphosphate and adenosine 5'monophoshate. In-Methods of Enzymatic Analy-sis, ed. H.U. Bergmeyer, Verlag Chemie-Academic Press, Weinheim-London, pp. 2127-2131.

Kearney, E.B. and Kun, E. (1974), Ammonia. InMethods of Enzymatic Analysis, ed. H.U. Bergmeyer, Verlag Chemie-Academic Press, WeinheimLondon, pp. 1802-1806.

Kelmer-Bracht, A.M., Fedatto-Júnior, Z., IshiiIwamoto, E.L., Caparroz-Assef, S.M., Bracht, A. (2002), The influence of $\mathrm{Ca}^{2+}$ on gluconeogenesis stimulation by glucagon in the liver of arthritic rats. Braz. Arch. Biol. Technol., 45, 309-315.

Kepler, D. and Decker, K. (1974), Glycogen: Determination with amyloglucosidase. In-Methods of Enzymatic Analysis, ed. H.U. Bergmeyer, Verlag Chemie-Academic Press,. Weinheim-London, pp. 1126-1131.

Kleckner, N.W., Kisaki, Z. and Thurman, R.G. (1987), Potential intercellular futile cycling of carbohydrates in diabetes. Biochem. J., 246, 417-423.

Kim, D., Klein, J.D., Racine, S., Murrell, B.P. and Sands, J.M. (2005), Urea may regulate urea transporter protein abundance during osmotic diuresis. Am. J. Physiol., 288, F188-F197.

Lamprecht, W. and Trautschold, I. (1974), Adenosine5 '-triphosphate. Determination with hexokinase and glucose-6-phosphate dehydrogenase. In-Methods of Enzymatic Analysis, ed. H.U. Bergmeyer, Verlag Chemie-Academic Press, Wein-heim-London, pp. 2101-2110.
Mouterde, O., Claeyssens, S., Chedevi, A. and Lavoinne, A. (1992), Glutamine is a good substrate for glycogen synthesis in isolated hepatocytes from 72 h-starved, but not from 24 h- or 48 h-starved rats. Biochem. J., 288, 795-799.

Portha, B., Levacher, C., Picon, L. and Rosselin, G. (1974), Diabetogenic effect of streptozotocin in the rat during the perinatal period. Diabetes 23, 889-895.

Rao, P. V., Pugazhenthi, S. and Khandelwal, R. L. (1995), The effects of streptozotocin-induced diabetes and insulin supplementation on expression of the glycogen phosphorylase gene in rat liver. J. Biol. Chem., 270, 24955-24960.

Sasse, D. (1975), Dynamics of liver glycogen: the topochemistry of glycogen synthesis, glycogen content and glycogenolysis under the experimental conditions of glycogen accumulation and depletion. Histochemistry, 45, 237-254.

Squires, S.A., Ewart, H., McCarthy, C., Brosnan, M.E. and Brosnan, J.T. (1997), Regulation of hepatic glutaminase in the streptozotocin-induced diabetic rat. Diabetes, 46, 1945-1949.

Scholz, R. and Bücher, T. (1965), Hemoglobin-free perfusion of rat liver. In-Control of Energy Metabolism, ed. B. Chance, R.W. Estabrook, and J. R. Williamson, Academic Press, New York, pp. 393414.

Wagle, S.R., Ingebretsen, W.R.Jr. and Sampson, L. (1975), Studies on gluconeogenesis and stimulation of glycogen and protein synthesis in isolated hepatocytes in alloxan diabetic, normal fed and fasted animals. Acta Diabetol. Lat., 12, 185-198.

Received: February 17, 2006; Revised: June 29, 2006; Accepted: March 20, 2007. 